\title{
Bulk Behavior of Ball Milled AA2124 Nanostructured Powders Reinforced with TiC
}

\author{
Hanadi G. Salem, ${ }^{1}$ Sherif El-Eskandarany, ${ }^{2}$ Amr Kandil, ${ }^{2}$ and Hassan Abdul Fattah ${ }^{2}$ \\ ${ }^{1}$ Department of Mechanical Engineering, The Yousef Jameel Science and Technology Research Center, \\ The American University in Cairo, AUC Avenue, New Cairo 11835, Egypt \\ ${ }^{2}$ Department of Mining, Metallurgy and Petroleum Engineering, Al-Azhar University, Cairo 11371, Egypt \\ Correspondence should be addressed to Hanadi G. Salem, hgsalem@aucegypt.edu
}

Received 22 November 2008; Accepted 9 April 2009

Recommended by Alan K. T. Lau

\begin{abstract}
In the current research work, a top-down approach was employed for the refinement of a micron scale AA2124 alloy powder $40 \mu \mathrm{m}$ in average size using high-energy ball milling up to 60 hours. The produced nanopowders were investigated compared to the micron gas atomized powder both in the monolithic and the reinforced composite states. $1 \mu \mathrm{m}$ powder of TiC with internal structure $<100 \mathrm{~nm}$ was used for the reinforcement of the 2124-Al matrices. Milling time of 36 hours produced a $<100 \mathrm{~nm}$ nanopowders with internal structure size $<20 \mathrm{~nm}$. The nanopowder monolithic consolidates exhibited compressive strength of $388 \mathrm{MPa}$ compared to $313 \mathrm{MPa}$ for micronpowder one. Addition of TiC nanostructured powder to the nanopowder consolidated matrix resulted in increase of $130 \%$ in compressive strength compared to that produced for the microscale one. Nanopowder of Alalloys produced by mechanical milling reinforced with $10 \mathrm{wt} \% \mathrm{TiC}$ is recommended for products suitable for high wear and erosion resistance applications. Peak aging increased the hardness and compressive strength of the as compacted micronpowder matrices by an average of $188 \%$ and $123 \%$, while increased that of the nanopowder matrices by an average of $110 \%$ and $117 \%$, respectively.
\end{abstract}

Copyright ( $) 2009$ Hanadi G. Salem et al. This is an open access article distributed under the Creative Commons Attribution License, which permits unrestricted use, distribution, and reproduction in any medium, provided the original work is properly cited.

\section{Introduction}

Composite materials are known for their multiple functionalities due to the ability of tailoring the composite properties through controlling the type, composition, and morphology of the matrix and reinforcement. Metal Matrix Composite (MMC) has been developed to meet specific properties that cannot be met by a monolithic material regardless of its composition or processing technique (thermomechanical treatment). MMC can be tailored in different methods depending on the type and shape of the reinforcing phase (dispersion, particulate, whiskers, or fiber) and the consolidation technique produced to produce the bulk product [1]. The sintering behavior of metal matrix nanocomposites has been investigated for different matrices such as $\mathrm{Ti}[2]$, $\mathrm{Cu}$ [3], and Al-matrices [1, 4-9] with various ceramic reinforcements. Ti and Al-powders suffer from the formation of an oxide stable and brittle film, which strongly influences the consolidation behavior of the produced consolidates and hence their mechanical and physical properties [2].

Metal matrix composites reinforced with ceramic reinforcements have been extensively studied over the last two decades for their significant use in aerospace aircraft, automobile, and military applications [4-9]. Reinforcement of micron scale ceramic particles used to improve the yield and ultimate strength of the matrix metal on the expense of loosing toughness and ductility. Al-composites exhibit high specific strength and modulus, low density. AA2024 metallic powders became of great interest as matrices suitable for particulate reinforcement with ceramic powders especially $\mathrm{SiC}[10-13]$.

Carbides, oxides, and nitrides powder have been used extensively for the reinforcement of Alalloys. In specific, $\mathrm{SiC}$ and $\mathrm{Al}_{2} \mathrm{O}_{3}$ were the commonly used ceramic reinforcements. $\mathrm{TiC}$ was not investigated enough as a ceramic reinforcement to Alalloys; however, it has been receiving much attention 
TABLE 1: Chemical composition (wt\%) of the AA2124 metallic matrix and TiC powders.

\begin{tabular}{|c|c|c|c|c|c|c|c|}
\hline Matrix Powder & $\mathrm{Cu}$ & $\mathrm{Mg}$ & $\mathrm{Mn}$ & $\mathrm{Si}$ & $\mathrm{Fe}$ & \multicolumn{2}{|c|}{$\mathrm{Al}$} \\
\hline AA2124 & $3.8-4.0$ & $1.4-1.6$ & $0.5-0.7$ & $0.1 \max$ & $0.1 \max$ & \multicolumn{2}{|c|}{ Balance } \\
\hline Reinforcement Powder & Total C & Free C & $\mathrm{Fe}$ & $\mathrm{N}_{2}$ & $\mathrm{O}_{2}$ & Wax & $\mathrm{Ti}$ \\
\hline $\mathrm{TiC}$ & 19.71 & 0.16 & 0.20 & 0.30 & 0.87 & 0.15 & Balance \\
\hline
\end{tabular}

lately for its high melting temperature $(3373 \mathrm{~K})$, low thermal coefficient of expansion, extraordinary hardness, excellent wear, and abrasion resistance [14]. The MMC processing parameters have a significant effect on the properties of the produced bulk product. Amongst those parameters, we have type size and shape of both the metallic matrix and the reinforcement particles, as well as the consolidation technique, pressure, temperature, and time. Many studies focused on the effect of the particle size of the matrix relative to the reinforcement within the microscale [4-9]. Other studies focused on the powder consolidation process including hot compaction, Hot and cold isostatic pressing followed by sintering and recently, plasma activated sintering $[8,9]$.

Nanostructured materials exhibit relatively high interfacial energy compared to microstructural materials. The amount of energy stored by the nanostructured materials depends very strongly on the sensitization and processing techniques used for producing Bulk nanostructures material (BNSM). Several techniques have been employed for the synthesis of nanopowders, such as powder atomization and mechanical milling [15-17]. Mechanical milling especially ball milling produces nanopowders with very high stored energy induced by the continuous impact of the powder particles with stainless steel balls. The nature of interaction of the hardened balls and powder particles results in the strain hardening of the particles followed by their fragmentation into finer ones [18]. The amount of stored energy depends on the type of material, the milling time, speed, and temperature. For Alalloys, grain size of $20 \mathrm{~nm}$ was reported by Lin et al. [19], which was measured using XRD patterns and observed by TEM.

Nanoscale materials have been the subject of major interest in recent years due to the anticipated ultrahigh strength and toughness combination that can be achieved in contrast to materials with conventional meso and microscale structures [1-3]. Reinforcement with nanoscale ceramic powders or the use of nanostructured powders of both the matrix and reinforcement producing nanocomposites derived the attention of the researchers to produce ultrahigh strength/tough MMCs. The key issue lies in the optimization of the processing parameters suitable for the production of BNSM with superior properties suitable for high and cryogenic temperature applications. It has been reported that extrusion of a cryomilled nanostructured $\mathrm{Al}-\mathrm{Mg}$ alloy with grain size of $20-30 \mathrm{~nm}$ resulted in grain size coarsening up to $90 \mathrm{~nm}$ [19]. The degree of grain size coarsening is significantly affected by the alloying elements in the $\mathrm{Al}$ alloy, which controls the thermal stability of the powder during the consolidation stages.
Consolidation of bulk products starting from nanopowders represents an additional challenge for materials designed with superior properties. BNSM produced from the consolidation of mechanically milled powders could produce products with promising superior properties due to the relatively produced fine high energetic hard powders. On the other hand, the high hardness induced in the milled powder particles retards the particles' deformation during the compaction stages that is necessary for filling the empty spaces formed in between the particles to enhance consolidation. Accordingly, this research aims for the production of sound BNS consolidates of nanopowders with improved mechanical properties over those of the micron powder of the same material. This involves the fabrication of a nanoscale AA2124 powder by mechanical milling of a microscale as-received powder using high-energy ball milling. Influence of the hot compaction parameters on the consolidation behavior of the milled powders compared to the as-received one is investigated. Effect of ceramic nanopowders reinforcement additions on the consolidation behavior of both matrices is also investigated.

\section{Materials and Experimental Procedure}

In the current research, a top-down approach was employed for the refinement of a gas atomized micronpowders of AA2124 alloy with particle size ranging between $5-85 \mu \mathrm{m}$ with an average size of $40 \mu \mathrm{m}$. The as-received AA2124 and $\mathrm{TiC}$ powders were supplied by the Aluminum powder Company limited (APC) and Mitsuwa Chemicals Co. LTD, respectively. The chemical composition for the Al 2124 powder and $\mathrm{TiC}$ is shown in Table 1 . The $\mathrm{TiC}$ particle size ranged between $0.85-5 \mu \mathrm{m}$ with an average size of $1.0 \mu \mathrm{m}$. The refinement process was conducted using a FRITCH high-energy ball milling up to 60 hours at $500 \mathrm{rpm}$ in agate jars with ball-to-powder ratio of $30: 1$. The ball milling investigation intervals were $6,12,24,36,48$, and 60 hours. Density measurement and the effect of the sample aspect ratio $\mathrm{h} / \mathrm{d}$ (height-to-diameter ratio) were characterized for the compact produced from powders milled for 24 and 36 hours compared to the as-received one. Influence of the matrices powder size and mechanical properties on the $\mathrm{TiC}$ ceramic reinforcement distribution was investigated for the 0 -hour powders (as-received micronpowder) and powders milled for 24 hours (nanopowders). A turbula mixer was employed for the production of mixtures of 5, 10, and $20 \mathrm{wt} \%$ of the $1 \mu \mathrm{m}$ TiC powder in both matrices.

$\mathrm{X}$-ray diffraction was used to determine the crystallite size of the milled powders compared to the as-received one. The X-Ray diffractometer used is a Diano Co, energized at 


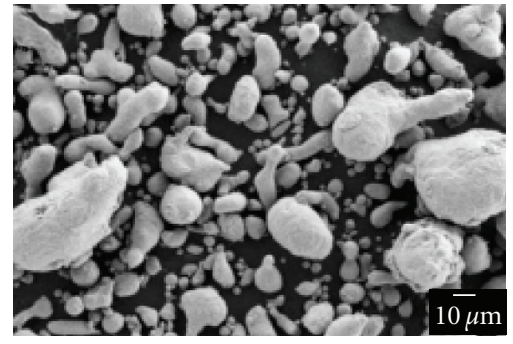

(a)

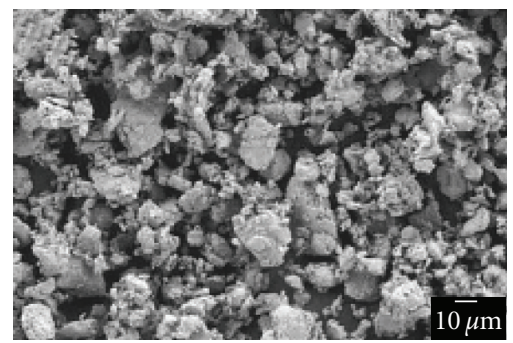

(c)

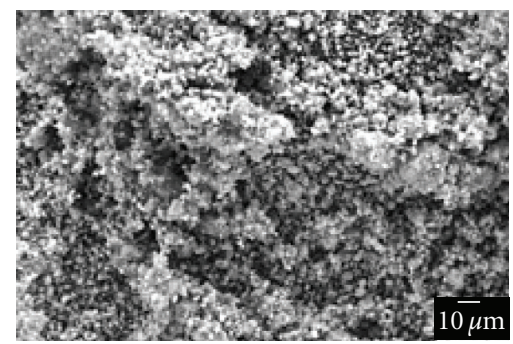

(e)

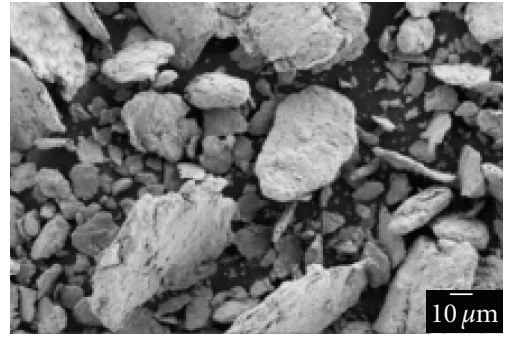

(b)

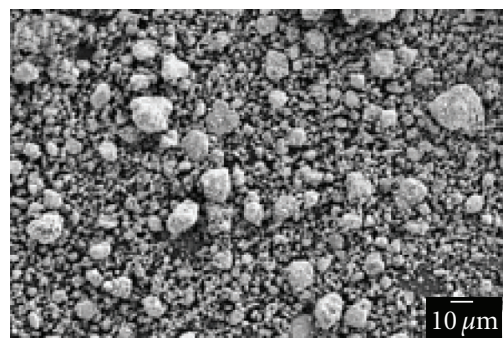

(d)

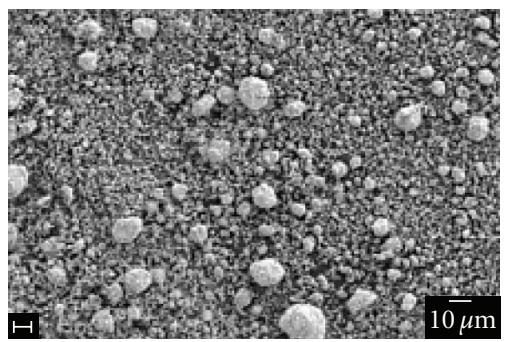

(f)

FIgURE 1: AA2124 particle morphology evolution with increasing milling time (a) 0 hour, (b) 6 hours, (c) 12 hours, (d) 24 hours, (e) 36 hours, and (f) 60 hours.

$45 \mathrm{kV}$ and $10 \mathrm{~mA}$ with a dead time of less than $10^{-6}$ seconds. A step scanning mode using Ni-filter $\mathrm{CuK} \alpha$ radiation was used to determine the crystallite size and to trace any structural changes that might have taken place during the refinement of the AA2124 powder during milling. A Leo high resolution filed emission scanning electron microscope (SEM) was employed to characterize the milled powder morphology and the topology of the compact samples.

The as-received and milled powders were consolidated into compacts using cold and hot unidirectional pressing at $624 \mathrm{MPa}$ with a pressing holing time of 30 minutes. Tool steel die with an inner diameter of $20 \mathrm{~mm}$ was used to consolidate the samples at $480^{\circ} \mathrm{C}(0.75 \mathrm{Tm})$. Height-todiameter aspect ratios (h/d) of $0.25,0.5$, and 1.0 for the compact samples were investigated for the micron (asreceived) and nanoscale ( 24 hours MT) matrices with and without TiC additions. A Licka optical microscope was used to investigate the microstructural evolution of the hot compacts (HCs) as a function of the various compaction parameters. Vickers microhardness was used to determine hardness of the consolidates using a Mitutoyo microhardness tester. The VHN measurements was conducted at $200 \mathrm{gm}$ for 15 seconds of dwell time. A minimum of 5 indentations were measured per condition. Compressive strength of the produced consolidates was evaluated using round $20 \mathrm{~mm}$ diameter and $5 \mathrm{~mm}$ height discs. A 50 tons MTS Universal testing machine was employed for conducting the compression tests at a cross-head speed of $0.5 \mathrm{~mm} / \mathrm{min}$. A minimum of 3-samples per condition was tested for compression, the average of which was reported.

\section{Results and Discussion}

In the current work, particle morphology and structure size were characterized for the ball milled as-received AA2124 powder for periods of $6,12,24,36,48$, and 60 hours. Densification of the compact AA2124 powders was characterized for the 0,24 , and 36 hours milling times.

3.1. Influence of Mechanical Iteration on the AA2124 Micronpowders. Figure 1 shows the SEM images of the milled powders after $0,6,12,24,36,48$, and 60 hours of milling time. The as-received microscale $\mathrm{Al}$-powder was made of irregular shaped particles with maximum size of $85 \mu \mathrm{m}$ and about 60 vol. $\%$ of the particles with sizes $<40 \mu \mathrm{m}$ (Figure $1(\mathrm{a})$ ). 


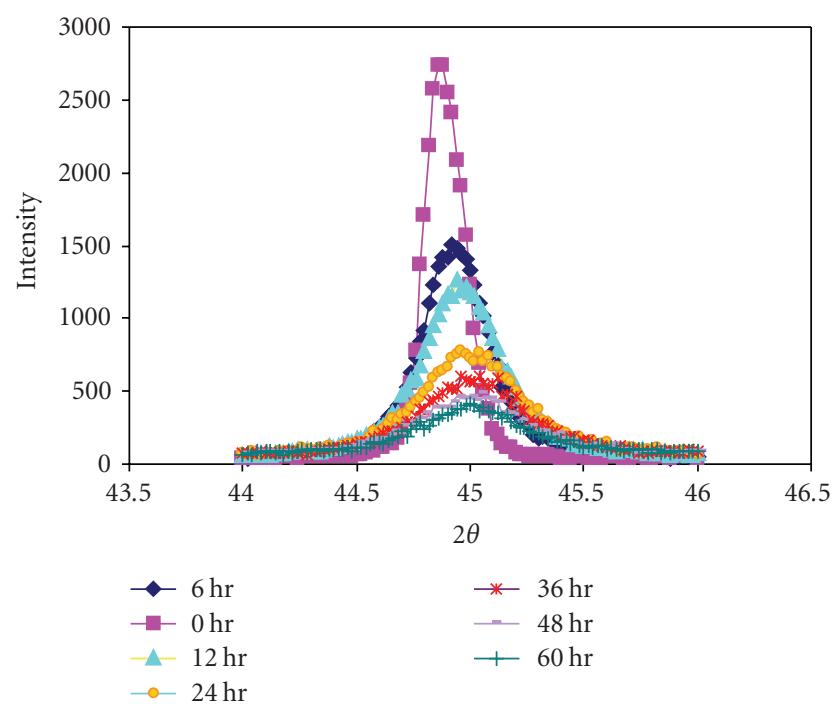

(a)

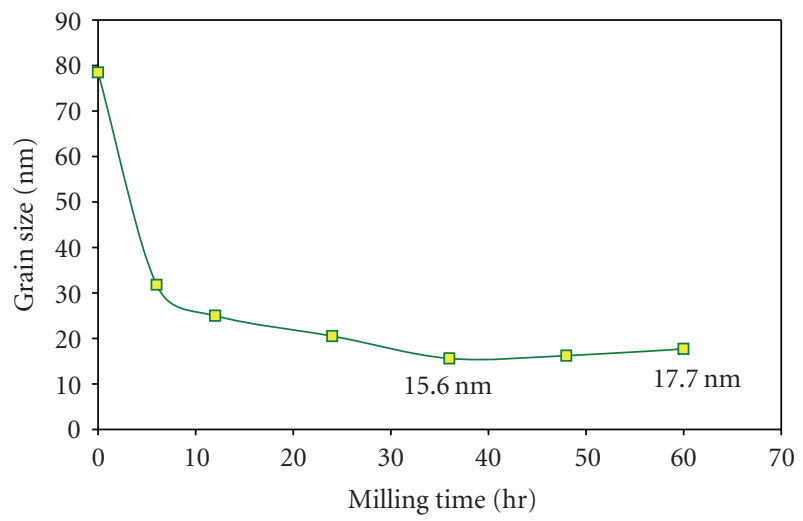

(b)

FIGURE 2: Effect of milling time on (a) X-ray diffraction $(200)_{\mathrm{Al}}$ peak and (b) crystallite size.

Figure 2 shows the corresponding XRD patterns for the powders as a function of the milling time (MT). After 6 hours of MT, the powder particles were severely deformed and agglomerated into disc-like flaky particles with 6-63 $\mu \mathrm{m}$ in size and $2-12.7 \mu \mathrm{m}$ in thickness. This was a result of the repeated welding during milling. This agrees with the observations made by Chen et al. who investigated the effect of milling time on Ni-Al alloys [20]. Further milling resulted in increased deformation and strain hardening, and hence the agglomerated discs were disintegrated into fragments of finer cluster ranging between $1-30 \mu \mathrm{m}$ in size (Figure 1(c)). Milling up to 24 hours produced sphericalshaped clusters of particles ranging between $5-45 \mu \mathrm{m}$. Those clusters were made of very fine particles $<300 \mathrm{~nm}$ in size, which were revealed easily at higher magnifications. Some of the refined powder was also observed separately scattered between the clusters (Figure 1(d)). Increasing the MT up to 36 hours produced ultrafine feathery like-shaped nanoscale powder $<100 \mathrm{~nm}$ in size that was agglomerated in clusters ranging between $2-30 \mu \mathrm{m}$ in size (Figure $1(\mathrm{e})$ ). Milling the
Al-powder for 48 followed by 60 hours did not result into further reduction of the individual particles' size below that produced at 36 hours; however, the cluster morphology developed into a more spherical well-defined clusters ranging between $0.3-11 \mu \mathrm{m}$ in size as shown in Figure 1(f). X-ray diffraction peaks from the $(200)_{\mathrm{Al}}$ planes show a significant decrease in intensity as well as broadening with increasing the MT from 0 to 60 hours.

To determine the powder grain size $(D)$, broadening of Xray diffraction peaks from the $(200)_{\mathrm{Al}}$ planes was employed for substitution in Scherrer's equation [5, 21]. Figure 2 shows the effect of milling time on the intensity and broadening of the $(200)_{\mathrm{Al}}$ peaks at $2 \theta=44^{\circ}$. Increasing the MT to 6 hours resulted in a significant refinement of the crystallite size from an average of 78-to-32 nm as shown in Figure 2(b). Further milling resulted in a gradual refinement in the crystallite size to a minimum of $15.6 \mathrm{~nm}$ at 36 hours of milling time. Increasing the MT above 36 hours did not result into further structural refinement. The observed slight increase in crystallite size up to $17.7 \mathrm{~nm}$ although insignificant could be due to the heat generated during the long period of MT up to 60 hours, which may result into coarsening of the nanoscale structure. Milling beyond 60 hours is necessary to trace the structural behavior with increasing MT.

3.2. Influence of the Powder Particle Morphology and Its Grain Size on the Green Compact Properties. The effect of particle size on the compaction relative density of the compacts was investigated. Milling times of 0,24 , and 36 were selected for this analysis. Figure 3 shows high magnification SEM images for the powders, which reveals the internal structure refinement of the powder as a function of milling time. The as-received powder (Figure 3(a)) shows that the powders have smooth surfaces with orange skinliked topology, which represents a typical morphology for the gas atomized powders. The average size of the observed internal structures was about $350 \mathrm{~nm}$. Finer particles do not reveal their internal structure which could be due to being much finer than that measured for the coarser particles. Powder milled for 24 hours shows clusters of fine particles with evidence for excessive deformation. Fine grains $<88 \mathrm{~nm}$ in size were revealed (marked by arrows in Figure 3(b)). Increasing the milling time to 36 hours revealed the formation of much finer clusters heavily deformed and very fine internal structure $<40 \mathrm{~nm}$ in size (marked by arrows in Figure $3(\mathrm{c})$ ). This agrees to a great extent with the crystallite size measurements produced by EDX analysis (Figure 2(a)).

Cold compaction was conducted in a die $20 \mathrm{~mm}$ in diameter for powder volumes that produced $\mathrm{h} / \mathrm{d}$ ratios of $0.25,0.5$, and 1.0 at a constant pressure of $624 \mathrm{MPa}$ for 30 minutes. Effect of particle size on the extent of densification was determined by Archimedes' principle using three randomly selected samples [22]. Figure 4 shows the effect of milling time on the degree of densification as a function of h/d ratio. Obviously, increasing the MT led to a decrease in the powders' particle size from an average of $40 \mu \mathrm{m}$-to- $90 \mathrm{~nm}$ produced green compacts with a lower 


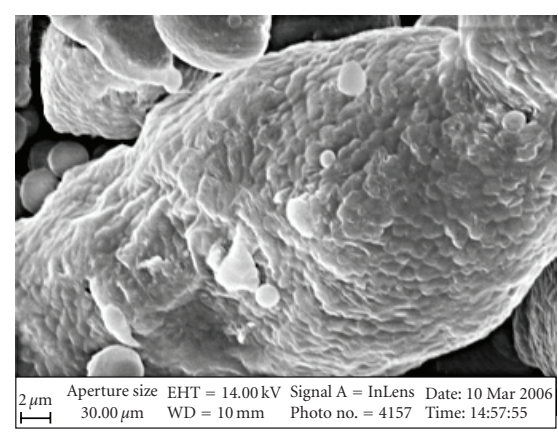

(a)

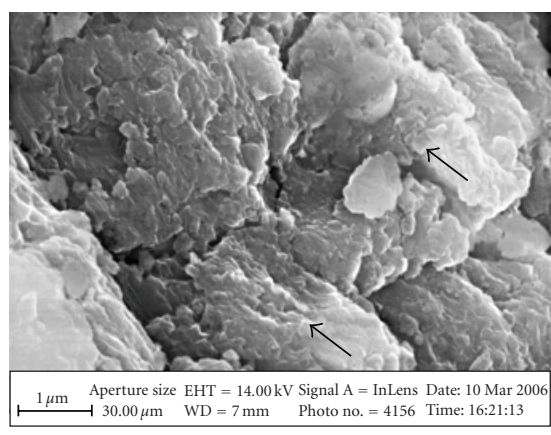

(b)

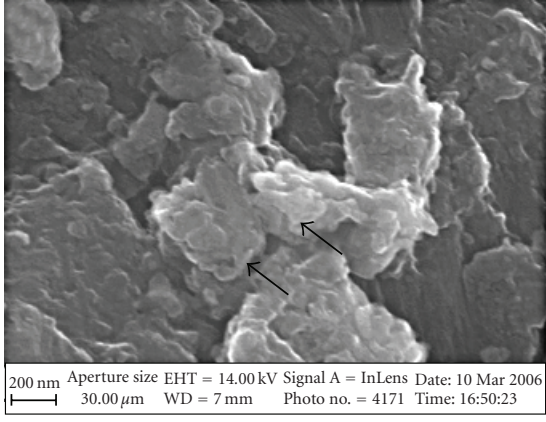

(c)

FIGURE 3: SEM micrographs for the (a) as-received powder, (b) 24 hours MT, and (c) 36 hours MT.

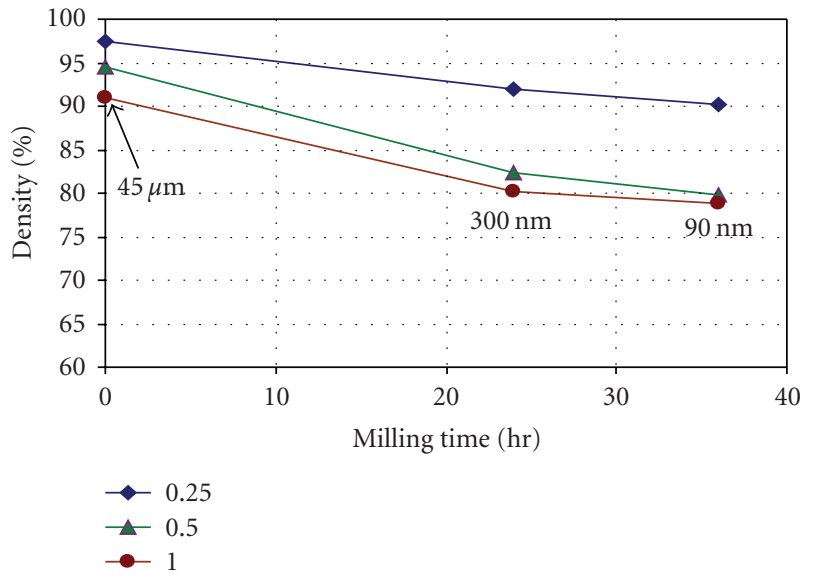

FIGURE 4: Effect of MT on the relative change in density of GC produced at compaction pressures of $624 \mathrm{MPa}$ for 30 minutes and $\mathrm{h} / \mathrm{d}$ ratios of $0.25,0.5$, and 1.0 .

density regardless of the $\mathrm{h} / \mathrm{d}$ ratio. On comparing the effect of $\mathrm{h} / \mathrm{d}$ ratio on the percent decrease in density for the $40 \mu \mathrm{m}$ ( 24 hours) and $90 \mathrm{~nm}$ (36 hours) particle sizes, about $13.4 \%$ and $7.5 \%$ were measured for $\mathrm{h} / \mathrm{d}$ ratio of 0.25 and 1.0 , respectively. This indicates that smaller $\mathrm{h} / \mathrm{d}$ ratio not only produced higher green compact densities but also improved the densification of the nanoscale particles compared to the microscale one.

Figure 5 shows high resolution SEM images at low and high magnifications for the $40 \mu \mathrm{m}$ (0 hour), $300 \mathrm{~nm} \mathrm{(24}$ hours) and $90 \mathrm{~nm}$ (36 hours) green compact powder at h/d ratio of 0.25 . It is observed that the 0 hour particles formed large porosity at triple points although finer particles were entrapped between the bigger ones. The 36 hours milled powder shows more uniform distribution of the pores in between the fragmented hard fine particles. For the 24-hour milled powders, particle refinement increased the particleto-particle contact surfaces, which reduced porosity. Higher magnification images revealed clearly the internal structure of the as-received 0 hour powders, which was about $500 \mathrm{~nm}$ in average size. On the other hand the milled powders for 24 and 36 hours images did not reveal the internal structure due to the intensity of plastic deformation induced by milling. The nanopowder green compaction behavior can be attributed to the resistance of the strain hardened nanopowders to the imposed pressure compared to that of the micronpowder, which agrees with the observations made by Srivatsan et al. [23].

3.3. Effect of TiC-Wt\% Reinforcement Additions on the Micro and Nanopowder AA2124 Matrices. The consolidation behavior of the as-received gas atomized micronpowder ( $40 \mathrm{~nm}$ particle size with $78 \mathrm{~nm}$ crystallite size) and the 24 hour milled nanopowders (300 nm particle size with $20 \mathrm{~nm}$ crystallite size) were mixed with $0,5,10$, and $20 \mathrm{TiC}$ wt $\%$ nanostructured powders. Figure 6 shows SEM micrographs at low and high magnifications for the $\mathrm{TiC}$ powder. The $\mathrm{TiC}$ particles are random in shape and range between $140 \mathrm{~nm}$ $5 \mu \mathrm{m}$ in size.

Characterization of the consolidation behavior of the produced nanocomposites was conducted for the green and hot compacts. After mixing of the powders, a compaction load of $624 \mathrm{MPa}$ for 30 minutes and $0.25 \mathrm{~h} / \mathrm{d}$ ratio were used for cold compaction. Figure 7 shows the effect of adding TiC nanostructured powder on the degree of densification of the AA2124 micro and nanopowders after cold compaction. It is clear that the observed decrease in density with the refinement of the powder from the micron to the nanoscale level of the bare matrix (Figure 4) was carried over to the produced densities of the reinforced condition for both the green and hot compacts. Hot compaction of the unreinforced matrices, however, resulted in a significant increase in density of both powders, especially for the nanoscale one. A $7 \%$ versus $2.4 \%$ increase in relative density was measured for the nano and microscale powders by hot compaction, respectively. It is suggested that powder milling for 24 hours resulted in the strain hardening of the produced powders, which hindered the deformation of the powder particles under the applied load used during cold compaction which resulted in the measured low density (92\%). Conversely, the as-received micronpowder produced by gas atomization is expected to be relatively soft, which facilitated the deformation and hence resulted in filling of the empty spaces between the individual powder particles. This could be sustained by the observations 


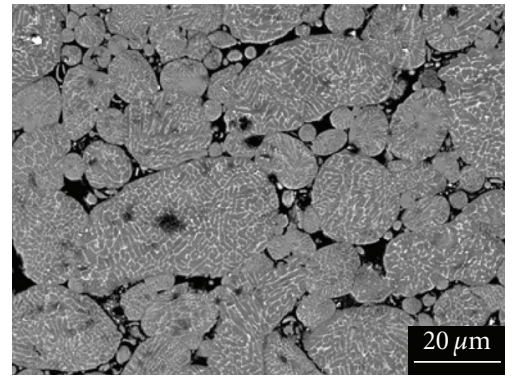

(a)

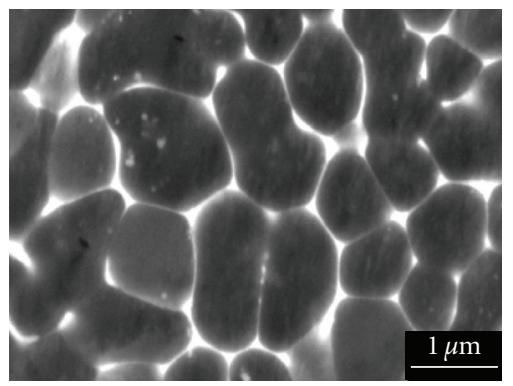

(d)

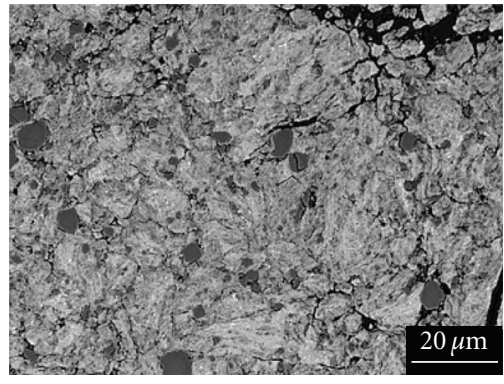

(b)

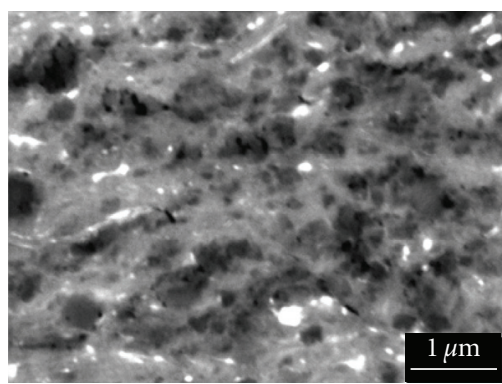

(e)

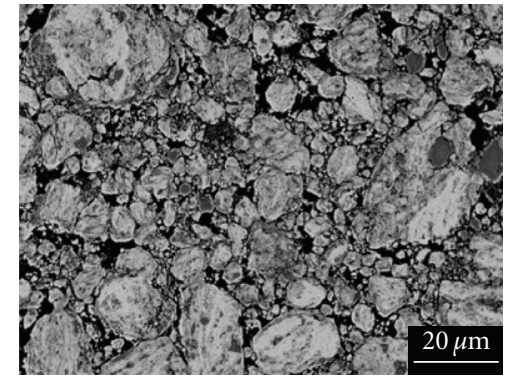

(c)

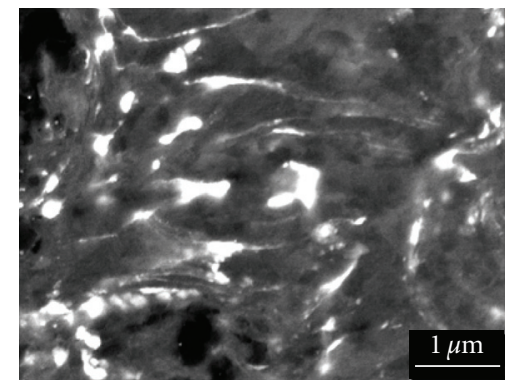

(f)

FIGURE 5: SEM images at low and high magnifications for the (a) $40 \mu \mathrm{m}$, (b) $300 \mathrm{~nm}$, and (c) $90 \mathrm{~nm}$ green compact powders with $0.25 \mathrm{~h} / \mathrm{d}$ ratio, respectively.

made in Figures 5(a) and 5(b). Heating of the nanopowders under pressure allowed for the sliding of fine individual nanoparticles and the small clusters to slide in between the coarser clusters, which enhances the densification of the produced hot compacts.

$5 \mathrm{wt} \%$ addition of TiC did not result in a noticeable change in the densification degree for both types of hot compact matrices. However, increasing the $\mathrm{TiC}$ content resulted in a significant decrease in relative density as shown in the figure. Further addition of $\mathrm{TiC}$ to both matrices resulted in deterioration in density of the produced compacts; although, hot compactions resulted in a significant enhancement in density. $9 \%$ and $7.4 \%$ increase in density was achieved by hot compaction of the nano and microscale reinforced matrices with $20 \mathrm{wt} \% \mathrm{TiC}$, respectively.

Figure 8 shows the SEM micrographs for the microscale and nanoscale $\mathrm{Al}$ matrix green compacts reinforced with 0 , 5,10 , and $20 \mathrm{wt} \% \mathrm{TiC}$. It was observed that reinforcement of the AA2124 matrices with $5 \mathrm{wt} \% \mathrm{TiC}$ resulted in the formation of isolated large voids especially in the microscale particles, which explains the significant decrease in density. It is clear that local diffusion between the micronparticles without reinforcement (Figures 8(a)-8(d)) was reduced significantly due to the accumulation of the TiC fine particles on the surface of the Al matrix particles. The difference in particle size of the $\mathrm{TiC}$ particles compared to the $\mathrm{Al}$ matrix particles promoted the lack of uniform distribution of the reinforcement within the matrix and hence resulted in the observed drop in density that was observed in Figure 7. Conversely, the nanoscale $\mathrm{Al}$ matrix did not suffer a significant drop in density by adding $\mathrm{TiC}$ particles compared to the unreinforced condition (Figure 8(e)) due to the size compatibility with the matrix fine agglomerates, which can be observed at higher magnification images shown in Figures $8(\mathrm{f})-8(\mathrm{~h})$.

In the microscale matrix composite green compacts (Figures $8(\mathrm{~b})$ and $8(\mathrm{c}))$ the observed pores were formed between the individual particles, while in the nanopowder matrix two types of pores were observed (a) large interagglomerate pores and (b) small pores between the individual nanoparticles (Figures $8(\mathrm{f})$ and $8(\mathrm{~g})$ ). It is clear that localization of the reinforcement is occurring between the particles of the nanoparticles and the agglomerates of the nanopowder clusters. This agrees with the findings of Srivatsan et al. [23]. Previous investigations revealed that a green compact densification can increase if the applied pressure during compaction breaks down the agglomerates, which produces homogeneous small interparticle pore distribution. This in turn will improve the consolidate properties. Breaking down of the agglomerated cluster depends on the powder fabrication method, which controls the degree by which the agglomerated clusters resist deformation [23].

The observed decrease in density with addition of TiC to the nanopowder matrix disagrees with the produced increase in density observed by El-Eskandarany, who investigated the effect of adding $\mathrm{SiC}$ to $\mathrm{Al}$ matrix [8]. This could be explained by the difference in processing of the nanocomposites in both cases. El-Eskandarany produced the nanoscale composite through the simultaneous ball milling of $\mathrm{SiC}$ reinforcing particles with the $\mathrm{Al}$ matrix and produced $\mathrm{Al} / \mathrm{SiC}$ nanocomposite particles made out of uniformly distributed nanoparticles of the reinforcement phase encapsulated within $\mathrm{Al}$ 


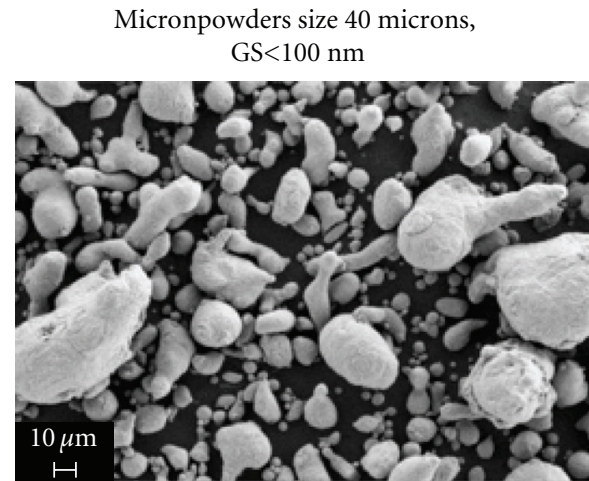

(a)

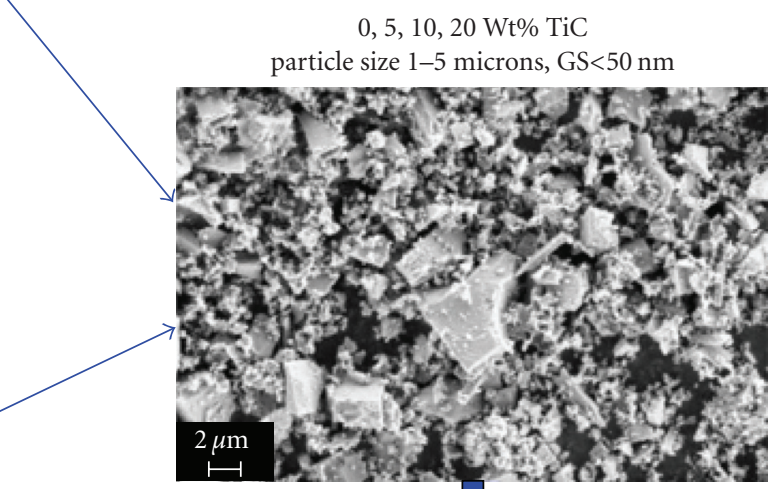

Nanopowders size $<300 \mathrm{~nm}$, GS $20 \mathrm{~nm}$

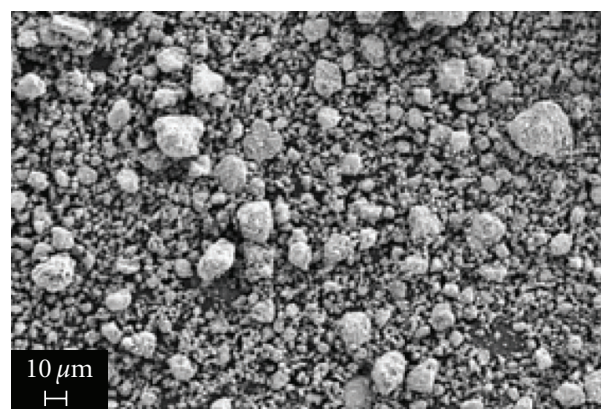

(c)

(b)

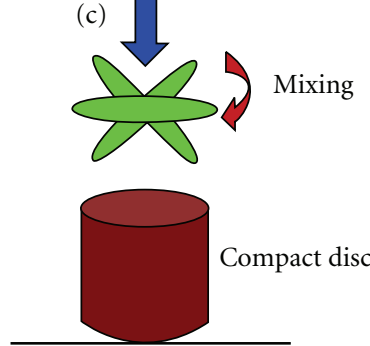

Green and hot compaction $624 \mathrm{MPa}, 480^{\circ} \mathrm{C}(\mathrm{h} / \mathrm{d}=0.2)$

(d)

FIgURE 6: SEM images for (a) as-received microcrystalline micronpowder, (b) Nanocrystalline nanopowders milled 24 hours, (c) TiC powder, and (d) compaction conditions of the produced mixtures.

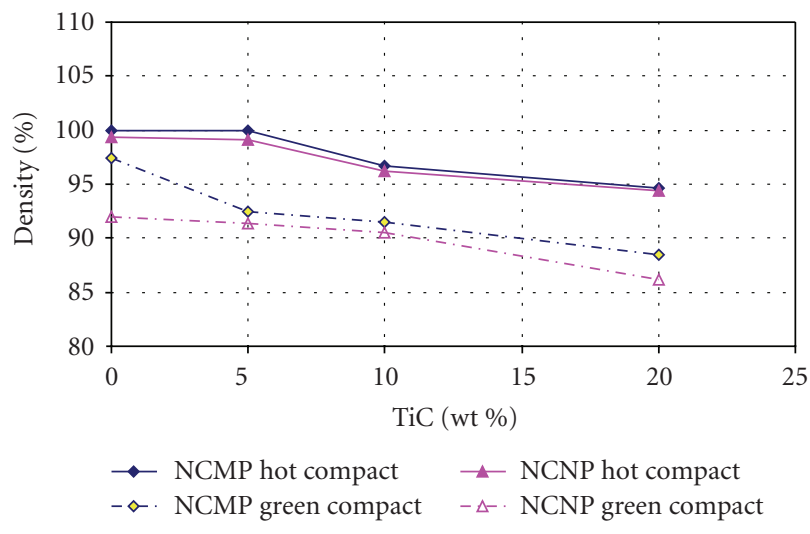

FIgURE 7: Effect of TiC addition on the density variation of the micro and nanopowder matrices green and hot compacts.

matrix. Hence the densification process is expected to be different from that used in the current research, where the $\mathrm{Al}$ matrix was first refined via ball milling into the nanopowder matrix followed by mixing it with the TiC particles. This could have resulted in the segregation of the reinforcing particulates along the boundaries between the $\mathrm{Al}$ matrix nanoparticles. As a result a lack of diffusion between the particles occurred and hence increased the void volume fraction. This was confirmed through investigation of the green compact specimens using SEM.

In order to investigate the mechanical behavior of $\mathrm{HC}$ micronpowder versus the nanopowder with and without TiC reinforcement, microhardness testing was conducted. Note, the microhardness testing investigates the particle-toparticle bond strength regardless of the densification degree, since the performed indentations were conducted only in dense consolidated regions on the surface of the specimen. Figure 9 shows the effect of TiC additions on the VHN-values produced for both the micro and nanoscale hot compacts matrices.

It is observed that the hardness of the monolithic nanopowder $\mathrm{HC}$ is higher than that of the micron one by 


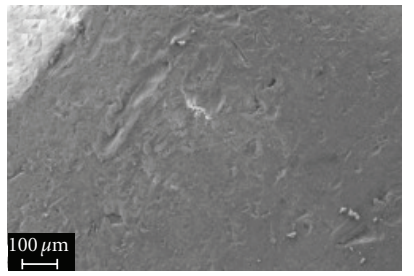

(a)

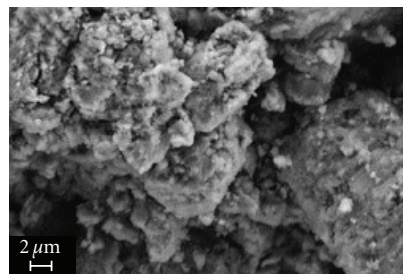

(e)

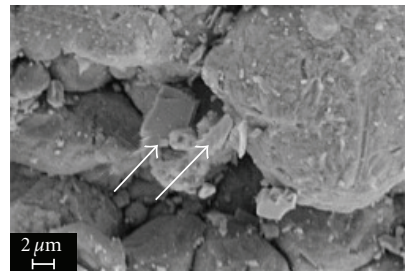

(b)

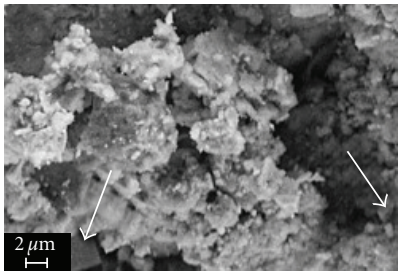

(f)

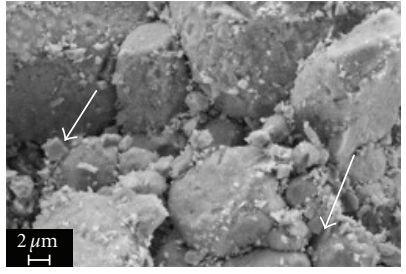

(c)

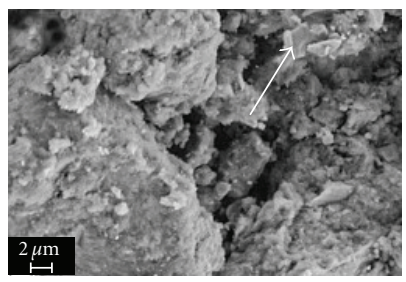

(g)

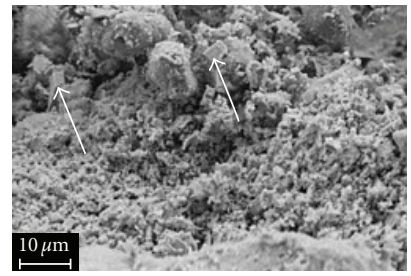

(d)

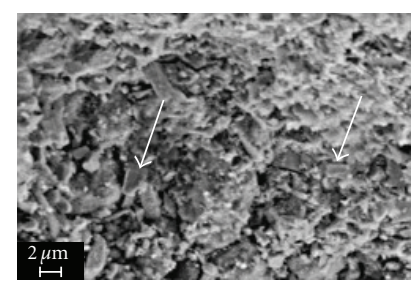

(h)

FIGURE 8: High magnification SEM micrographs for the micro (a)-(d) and nanoscale (e)-(h) green matrices reinforced with 0 , 5, 10, and $20 \mathrm{wt} \% \mathrm{TiC}$, respectively. Arrows point at TiC particles.

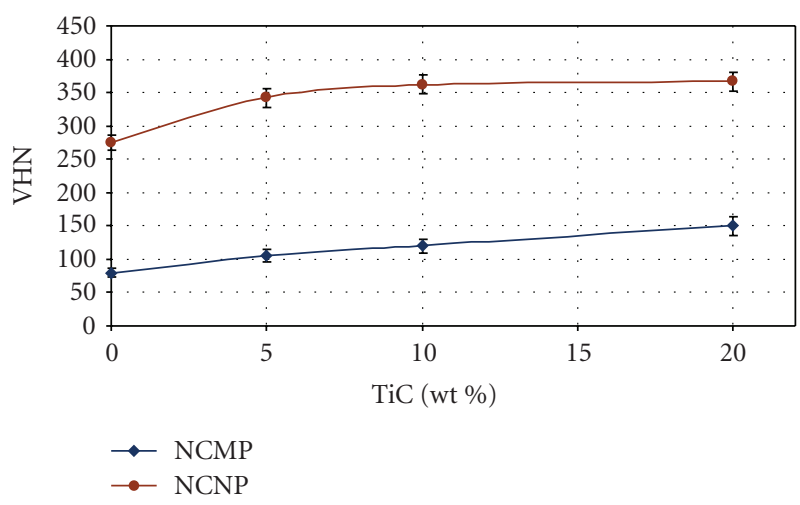

Figure 9: A graph showing the Effect of TiC addition on the microhardness for the as-received micron and nanopowder consolidated HC.

343\%. Similar observations were made by Chen et al., on nanocrystalline $\mathrm{NiAl}$ milled powders [20]. Addition of $5 \mathrm{wt} \%$ $\mathrm{TiC}$ to the nanopowder $\mathrm{HC}$ resulted in a $124 \%$ increase in hardness of the monolithic one compared to an increase of $132 \%$ for the micronpowder HC. Increasing the TiCcontent beyond $5 \mathrm{wt} \%$ did not result in a noticeable increase in hardness, especially for the nanopowder compacts, while a gradual increase in hardness was observed for the micronpowder matrix reinforced with up to $20 \mathrm{wt} \%$.

The compressive strength measured for the AA2124/TiC composite materials obtained by hot compaction for the micro and nanopowder compact matrices with and without TiC reinforcement is displayed in Table 2 and Figure 10. It is observed that refinement of the micronpowder to the nanoscale level by ball milling produced hot compact discs not only with significantly enhanced hardness values, but also with enhanced compressive strength. The nanopowder monolithic consolidates exhibited compressive strength of $388 \mathrm{MPa}$ compared to $313 \mathrm{MPa}$ for micronpowder one,

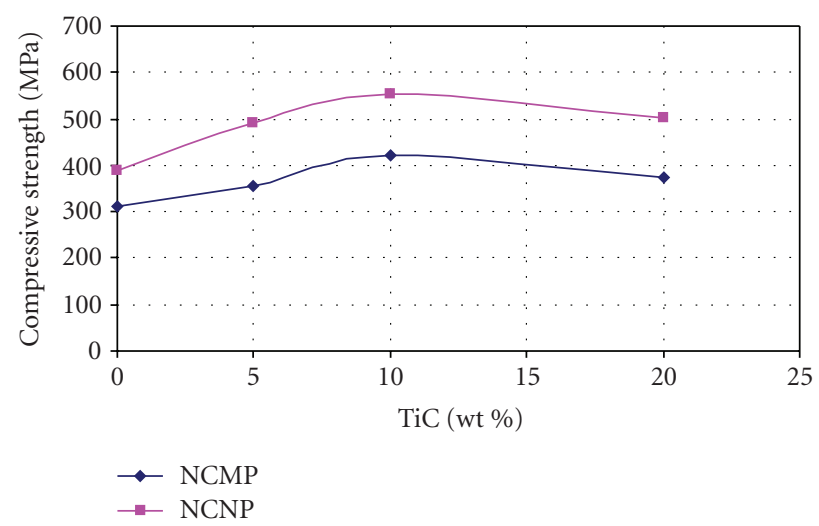

Figure 10: Compressive strength of HC micro and nanopowder consolidates as a function of TiC additions.

TABLE 2: Effect of TiC additions to the micron and nanopowder matrices.

\begin{tabular}{ccc}
\hline TiC wt\% & $\begin{array}{c}\text { Compressive strength } \\
\text { (MPa) } \\
\text { (micronpowder } \\
\text { matrices) }\end{array}$ & $\begin{array}{c}\text { Compressive strength } \\
(\mathrm{MPa}) \text { (nanopowder } \\
\text { matrices) }\end{array}$ \\
\hline 0 & 313.66 & 389 \\
5 & 357.84 & 493.23 \\
10 & 415.55 & 538.57 \\
20 & 373.65 & 507.47 \\
\hline
\end{tabular}

which represents a $123 \%$ improved compressive strength. Addition of $\mathrm{TiC}$ nanostructured powder up to $20 \mathrm{wt} \%$ to the nanopowder consolidated matrix resulted in an average increase of $130 \%$ in compressive strength compared to that produced for the microscale one. From the diagram it is obvious that $10 \mathrm{wt} \% \mathrm{TiC}$ produced the highest compressive strength for both matrices, which decreased with increasing the content up to $20 \mathrm{wt} \%$. 


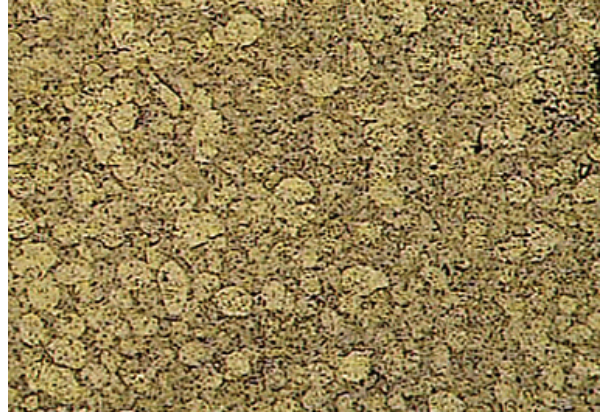

(a)

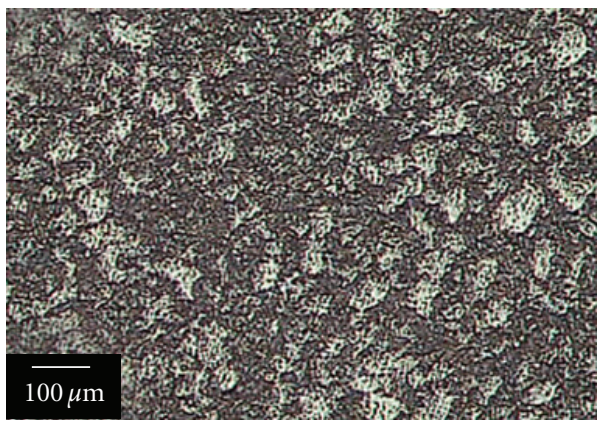

(c)

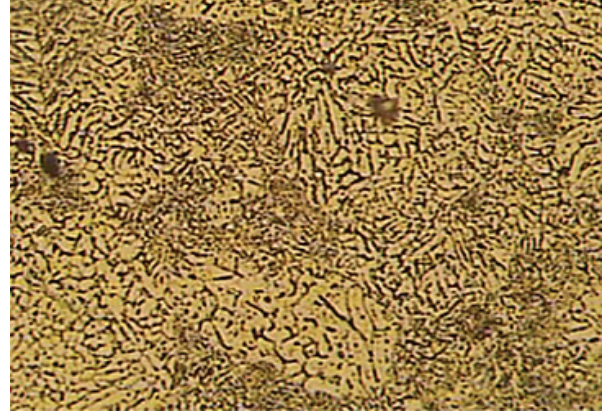

(b)

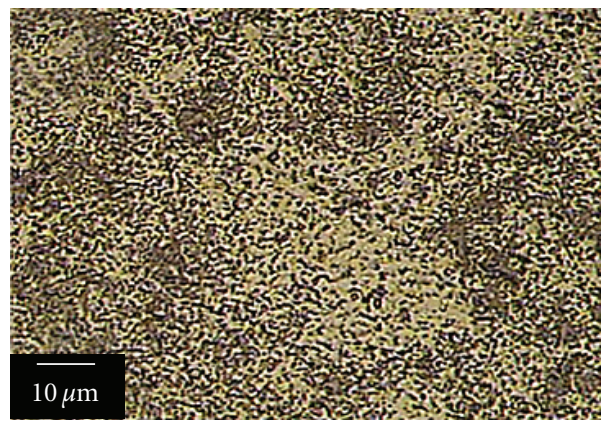

(d)

FIGURE 11: Optical micrographs at low and high magnifications showing the microstructure of the hot compact discs produced for the monolithic (a), (b) micronpowder and (c), (d) nanopowder HC AA2124.

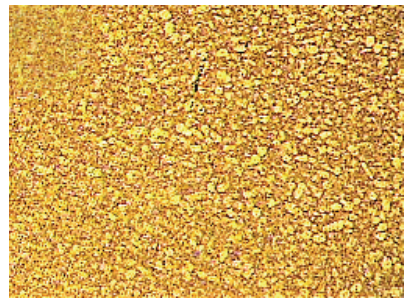

(a)

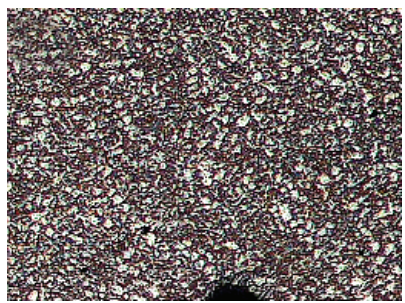

(e)

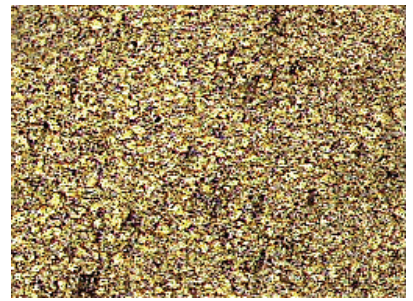

(b)

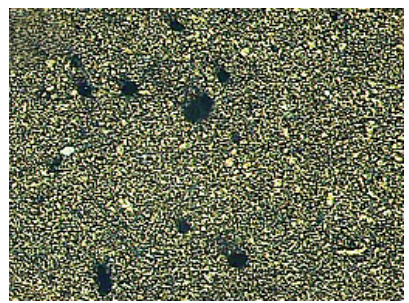

(f)

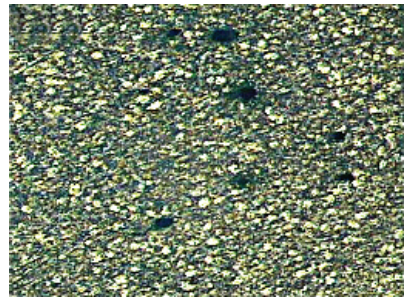

(c)

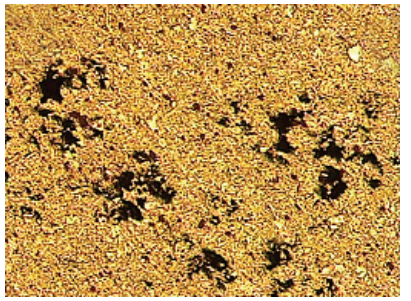

(g)

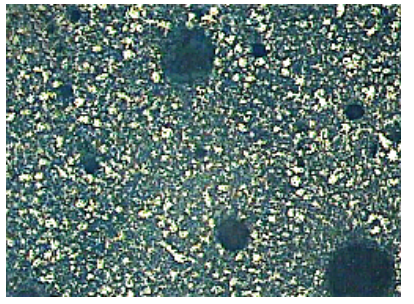

(d)

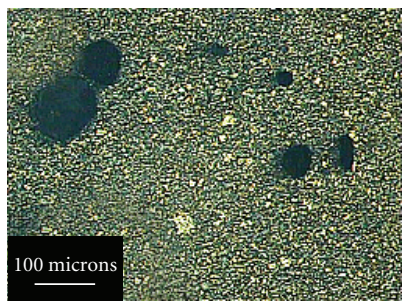

(h)

Figure 12: OM micrographs showing low magnification images for the (a)-(d) micronpowder 0, 5, 10, and 20\%, and (e)-(h) nanopowder $0,5,10$, and $20 \%$ consolidated HC matrices, respectively.

Investigation of the hot compacts microstructure at low and high magnification (Figure 11) explained the difference in VHN-values for both matrices. The consolidated micronpowder particle size was measured to be $<50 \mu \mathrm{m}$ (Figure 11(a)) for the grain size $2 \mu \mathrm{m}$ in average size (Figure 11(b)). On the other hand, the ultrafine structure size produced by hot compaction of the nanopowders was not revealed by optical microscopy as shown in Figures 11(c), 11(d). This suggests the possibility of retaining the nanoscale internal structure but as well as the nanoscale refined powder produced by 24 hours of MT. High strain hardening and stored energy in the nanostructure induced by the prior high-energy ball milling explain the observed improvement in hardness and compressive strength over the 


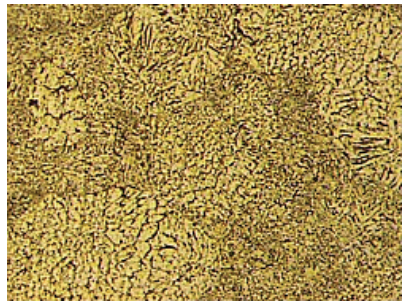

(a)

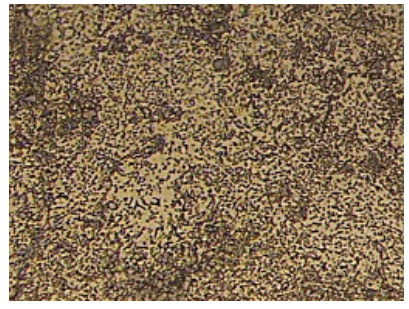

(e)

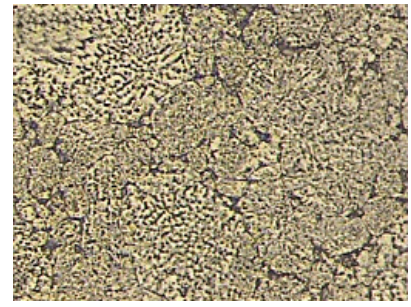

(b)

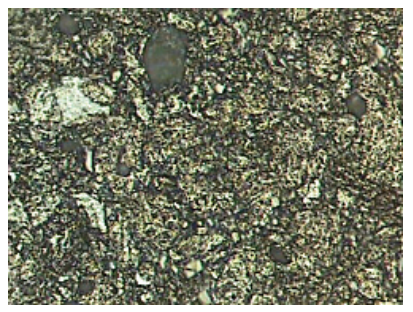

(f)

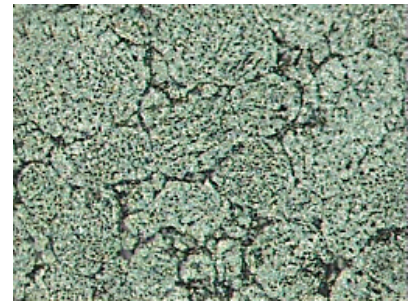

(c)

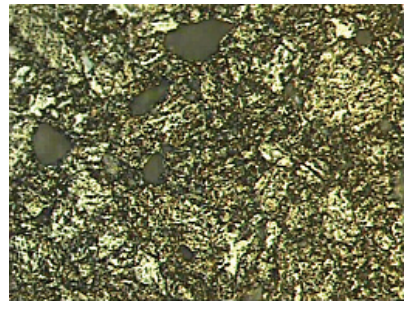

(g)

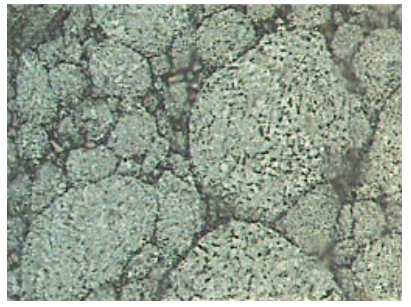

(d)

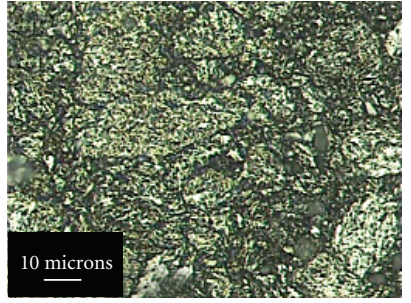

(h)

FIGURE 13: OM micrographs showing high magnification images for the (a)-(d) micronpowder 0, 5, 10, and 20\%, and (e)-(h) nanopowder $0,5,10$, and $20 \%$ consolidated HC matrices, respectively.

micronpowder consolidates. Additional investigations using transmission electron microcopy (TEM) is essential for the observation of the produced nanoscale structure along with the dislocation density after sintering.

Figure 12 shows the microstructural evolution as a function of $\mathrm{TiC}$ additions at magnifications images for the micron and nanopowder matrices, respectively. TiC-content increase within the micronpowder matrices above $5 \mathrm{wt} \%$ shows an increase in the voids size and volume fraction as shown in the low magnification images (Figures 12(c)12(d)). For the nanopowder HC matrices, TiC addition even with $5 \mathrm{wt} \%$ resulted in the formation of isolated voids which coalesced into larger voids and cavities when $\mathrm{TiC}$ content increased to $10 \%$ and $20 \%$ as shown in Figures 12(e)-12(f). Cavity and void formation was persistent in both matrices, especially for the AA2124/20\% TiC composite. It is suggested that the difference in thermal coefficient of expansion between the AA2 124 matrices and the TiC resulted in the observed voiding during the cooling stage after HC.

Figure 13 shows that higher magnification images show an increase in preferential clustering of the reinforcement phase along the matrix particles' boundaries and triple points with the increase in TiC-content as shown in Figures 13(a)13(d). Reinforcement segregation between the interstices of the relatively coarse micronpowder matrix particles during the compaction stage resulted in the formation of the reinforcement network particles along the matrix boundaries. The relative particle size (RPS) ratio of the matrix-to-reinforcement could be the cause of the observed segregation. Similar conclusions were depicted by Prasad et al. who investigated the effect of the RPS ratio of AA2124to-SiC [6]. Their studies showed that lower RPS ratio results in enhanced distribution of the reinforcement phase within the matrix and hence results into higher densification and improved mechanical properties.
Comparing the reinforced nanopowder $\mathrm{HC}$ matrices (Figures 13(e)-13(h)) with that of the micronpowder one (Figures 13(a)-13(d)), it is clear that the TiC particles were uniformly distributed within the nanopowder matrix with no signs of clustering along the matrix boundaries or triple points. An extremely strained matrix kinking around the TiC particles is shown at higher magnifications in the areas free from voids and cavities. It is worth noting that RPS ratios of $45: 1$ and $8: 1$ were measured for the micronpowder and nanopowder $\mathrm{HC}$ matrices, respectively, compared to those of the TiC reinforcement. Many studies were conducted on the effect of RPS ratio on Al-base alloys reinforced with ceramic particles $[6,24,25]$.

The observed intense matrix deformation around the TiC particles in addition to the strain hardening effect induced by ball milling of the matrix powder explains the exhibited increase in VHN values and compressive strength measured for the Nanopowder consolidated matrices compared to the micronpowder one. AA2124 is a precipitationhardenable alloy that contains different kind of second phase particles most important of which is the $\mathrm{Cu}$-rich phases which are responsible for the strengthening of the alloy on aging [1]. It is suggested that the diffusion mean free path of the $\mathrm{Cu}$ element is strongly affected by the reinforcement distribution within the matrix. The higher the RPS ratio, the higher the diffusion mean free path of $\mathrm{Cu}$ within the matrix which results in the segregation of the $\mathrm{Cu}$ rich phase within the reinforcement clusters and hence poor properties.

Further investigation is required to understand the consolidation behavior and deformation mechanism of the nanopowder matrix compared to the micropowder one with and without reinforcement. One of the major causes that might have contributed to the formed cavities is the problem of entrapped air pockets within the individual particles and agglomerates. The powder compaction stage was done 
TABLE 3: Effect of aging at $175^{\circ} \mathrm{C}$ on peak aging time, hardness, and compressive strength.

\begin{tabular}{lcccccc}
\hline \multirow{2}{*}{ TiC (wt.\%) } & \multicolumn{3}{c}{ Micronpowder matrices } & \multicolumn{3}{c}{ Nanopowder matrices } \\
& Peak aging time $(\min )$ & VHN & $\sigma_{\text {Comp }}(\mathrm{MPa})$ & Peak aging time $(\mathrm{min})$ & VHN & $\sigma_{\text {Comp }}(\mathrm{MPa})$ \\
\hline 0 & 560 & 190 & 377 & 530 & 305 & 458 \\
5 & 430 & 195 & 453 & 360 & 365 & 540 \\
10 & 300 & 220 & 508 & 270 & 375 & 636 \\
20 & 190 & 242 & 464 & 180 & 425 & 624 \\
\hline
\end{tabular}

in open air without the use of vacuum or inert gas. A much improved consolidation behavior is expected under controlled atmosphere. Moreover, metal forming after cold or hot compaction will without doubt increase density and hence enhance the mechanical behavior of the consolidated bulk specimens.

Investigation of the effect of aging time at $175^{\circ} \mathrm{C}$ was also investigated for the micron and nanopowder matrices in the monolithic and reinforced conditions. Table 3 shows the peak aging time for each condition as well as the exhibited VHN-values and compressive strength.

From Table 3, it is clear that increasing content of TiC to both matrices resulted in decreasing the peak aging duration from about 9 to 3 hours for the matrices reinforced with 0 up to $20 \mathrm{wt} \% \mathrm{TiC}$, respectively. On the other hand, the peak aging time recorded for the micron and nanopowder matrices was almost the same for all conditions. Peak aging increased the hardness of the as compressed micronpowder matrices (Figure 9) by an average of $188 \%$, while increased that of the nanopowder matrices by an average of $110 \%$. In addition, peak aging resulted in increasing the compressive strength of the micron and nanopowder matrices was $123 \%$ and $117 \%$ in average, respectively. This indicates that solution heat treatment at $500^{\circ} \mathrm{C}$ for 1 hour followed by peak aging at $175^{\circ} \mathrm{C}$ for hours did not result in the loss of the mechanical properties of the milled powders, but rather enhanced the mechanical properties. In order to explain the nanopowder mechanical behavior post solutionizing and aging structural evolution compared to that of the micronpowder matrices with and without reinforcement microstructural investigation is currently under investigation.

Comparing the continuously cast and rolled sheets of AA2124-T851 properties with those produced for the investigated 24 hours milled powder consolidates in the T6 temper condition, it is found that a hardness of $146 \mathrm{HV}$ versus $309 \mathrm{HV}$ is produced, respectively. In addition, the hot compact nanopowders reinforced with only $10 \mathrm{wt} \% \mathrm{TiC}$ displayed compressive strength that is higher $(636 \mathrm{MPa})$ than MMC of AA2124 micronpowder ( $75 \mu \mathrm{m}$ particle size) reinforced with either $10 \% \mathrm{BN}$ or $15 \% \mathrm{Al}_{2} \mathrm{O}_{3}$ processed by a combined cold uniaxial compaction followed by conventional extrusion at $480^{\circ} \mathrm{C}$ with an extrusion ratio of $3.25: 1$ [26]. This indicates a significant improvement in the load bearing capacity and durability of the fabricated Al-based nanocomposites, especially for applications that requires high performance at relatively high operating temperatures.

\section{Conclusions}

In the current paper, we have what follows.

(1) Nanocrystalline-nanopowders $<100 \mathrm{~nm}$ in particle size and $20 \mathrm{~nm}$ internal structural size were fabricated successfully by high-energy ball milling from a $40 \mu \mathrm{m}$ particle sized AA2124 powder with internal structure ranging between $53-300 \mathrm{~nm}$ in average size.

(2) The consolidation behavior of the micro and nano consolidated matrices was characterized in the monolithic condition and with addition of $\mathrm{TiC}$ ceramic nanostructured particles.

(3) The green compact densities of the nanoscale powder decreased to $92 \%$ compared to $97 \%$ for the micronpowder as-received powder. This was due to the resistance of the strain hardened agglomerates to the applied pressure used for compaction.

(4) The degree by which the density decreased with the addition of $5 \mathrm{wt} \% \mathrm{TiC}$ to the matrix was much lower for the nanoscale consolidated matrix compared to the micronpowder consolidated one due to the low RPS ratio between the matrix and the reinforcement, which promoted uniform distribution of the TiC particles within the matrix agglomerates.

(5) Increasing $\mathrm{TiC}$ content up to $10 \mathrm{wt} \%$ results in the formation of large voids and cavities, which reduces the compressive strength of the produced compacts, although hardness increases with TiC addition regardless of the content.

(6) Hardness and compressive strength increased by peak aging at $175^{\circ} \mathrm{C}$ for monolithic and composite consolidated nanostructured AA2124, which qualifies them for high performance load bearing light weight applications.

(7) Based on the current research nanopowder of Alalloys produced by 24 hours mechanical milling of gas atomized micronpowders reinforced with $10 \mathrm{wt} \%$. $\mathrm{TiC}$ is recommended for products suitable for high wear and erosion resistance applications.

(8) Further investigation is required using TEM for microstructural analysis on the nanoscale level. In addition, investigation of the compressive strength of the produced compacts with and without heat treatment is also planned. 


\section{Acknowledgment}

The authors of the work would like to acknowledge the Yousef Jameel Science and Technology Research Center (YJSTRC) at the American University in Cairo, Egypt for the financial support of the current research.

\section{References}

[1] J. C. Malas, S. Venugopal, and T. Seshacharyulu, "Effect of microstructural complexity on the hot deformation behavior of aluminum alloy 2024," Materials Science and Engineering A, vol. 368, no. 1-2, pp. 41-47, 2004.

[2] V. V. Dabhade, T. R. Rama Mohan, and P. Ramakrishnan, "Sintering behavior of titanium-titanium nitride nanocomposite powders," Journal of Alloys and Compounds, vol. 453, no. 1-2, pp. 215-221, 2008.

[3] J. Robertson, J.-T. Im, I. Karaman, K. T. Hartwig, and I. E. Anderson, "Consolidation of amorphous copper based powder by equal channel angular extrusion," Journal of NonCrystalline Solids, vol. 317, no. 1-2, pp. 144-151, 2003.

[4] S.-Y. Chang, K.-S. Lee, S.-H. Choi, and D. H. Shin, "Effect of ECAP on microstructure and mechanical properties of a commercial $6061 \mathrm{Al}$ alloy produced by powder metallurgy," Journal of Alloys and Compounds, vol. 354, no. 1-2, pp. 216220, 2003.

[5] S. H. Hong and K. H. Chung, "Effects of vacuum hot pressing parameters on the tensile properties and microstructures of SiC-2124 Al composites," Materials Science and Engineering A, vol. 194, no. 2, pp. 165-170, 1995.

[6] V. V. Bhanu Prasad, B. V. R. Bhat, Y. R. Mahajan, and P. Ramakrishnan, "Structure-property correlation in discontinuously reinforced aluminium matrix composites as a function of relative particle size ratio," Materials Science and Engineering A, vol. 337, no. 1-2, pp. 179-186, 2002.

[7] Z. Z. Chen and K. Tokaji, "Effects of particle size on fatigue crack initiation and small crack growth in SiC particulatereinforced aluminium alloy composites," Materials Letters, vol. 58, no. 17-18, pp. 2314-2321, 2004.

[8] M. S. El-Eskandarany, "Mechanical solid state mixing for synthesizing of SiCp/Al nanocomposites," Journal of Alloys and Compounds, vol. 279, no. 2, pp. 263-271, 1998.

[9] M. S. El-Eskandarany, "Structure and properties of nanocrystalline TiC full-density bulk alloy consolidated from mechanically reacted powders," Journal of Alloys and Compounds, vol. 305, no. 1-2, pp. 225-238, 2000.

[10] M. S. El-Eskandarany, T. J. Konno, M. Omori, et al., "Formation of refractory WC compound by mechanical solid state reduction," Journal of the Japan Society of Powder and Powder Metallurgy, vol. 43, no. 11, pp. 1368-1373, 1996.

[11] M. S. El-Eskandarany, T. J. Konno, M. Omori, et al., "Morphological and structural studies of mechanically alloyed $\mathrm{Ti}_{44} \mathrm{C}_{56}$ powders," Metallurgical Transactions A, vol. 27, p. 4210, 1996.

[12] X.-M. He, W.-Z. Li, and H.-D. Li, “Therapeutic application of molecular adsorbents recirculating system (MARS) in chronic severe hepatitis patients complicated with multiorgan failure," Journal of Materials Research, vol. 9, p. 2355, 1994.

[13] S. Xiang, K. Matsuki, N. Takatsuji, et al., "Microstructure and mechanical properties of PM 2024Al-3Fe-5Ni alloy consolidated by a new process, equal channel angular pressing," Journal of Materials Science Letters, vol. 16, no. 21, pp. 17251727, 1997.
[14] Y. Kim and J.-C. Lee, "Processing and interfacial bonding strength of $2014 \mathrm{Al}$ matrix composites reinforced with oxidized SiC particles," Materials Science and Engineering A, vol. 420, no. 1-2, pp. 8-12, 2006.

[15] K. I. Elkhodary, H. G. Salem, and M. A. Zikry, "Equal channel angular pressing of canned 2124-Al compacts: processing, experiments, and modeling," Metallurgical and Materials Transactions A, vol. 39, no. 9, pp. 2184-2192, 2008.

[16] H. G. Salem and M. Shamma, "Effect of the compaction parameters and canning material of nanostructured Alpowder consolidated via intense plastic straining process," in Proceedings of the ASME 2nd Multifunctional Nanocomposites and Nanomaterials Conference and Exhibition (MN '08), pp. 129-142, Sharm El Sheikh, Egypt, January 2008, CD-ROM.

[17] A. A. Sadek and H. G. Salem, "Construction of consolidation maps of Pre-ECAE hot compact nanocrystalline-micron powders," in Proceedings of the ASME 2nd Multifunctional Nanocomposites and Nanomaterials Conference and Exhibition (MN '08), pp. 39-46, Sharm El Sheikh, Egypt, January 2008, CD-ROM.

[18] B. Farrokh and A. S. Khan, "Grain size, strain rate, and temperature dependence of flow stress in ultra-fine grained and nanocrystalline $\mathrm{Cu}$ and $\mathrm{Al}$ : synthesis, experiment, and constitutive modeling," International Journal of Plasticity, vol. 25, no. 5, pp. 715-732, 2009.

[19] Z. Lin, S. L. Chan, and F. A. Mohamed, "Effect of nano-scale particles on the creep behavior of 2014 Al," Materials Science and Engineering A, vol. 394, no. 1-2, pp. 103-111, 2005.

[20] T. Chen, J. M. Hampikian, and N. N. Thadhani, "Synthesis and characterization of mechanically alloyed and shockconsolidated nanocrystalline NiAl intermetallic," Acta Materialia, vol. 47, no. 8, pp. 2567-2579, 1999.

[21] G. W. Dieter, Mechanical Metallurgy, McGraw-Hill, New York, NY, USA, 3rd edition, 1990.

[22] C. Suryanarayana and M. Norton, X-Ray Diffraction: A Practical Approach, Plenum Press, New York, NY, USA, 1998.

[23] T. S. Srivatsan, B. G. Ravi, M. Petraroli, and T. S. Sudarshan, "The microhardness and microstructural characteristics of bulk molybdenum samples obtained by consolidating nanopowders by plasma pressure compaction," International Journal of Refractory Metals and Hard Materials, vol. 20, no. 3, pp. 181-186, 2002.

[24] C. Raghunath, M. S. Bhat, and P. K. Rohatgi, "In situ technique for synthesizing Fe-TiC composites," Scripta Metallurgica et Materiala, vol. 32, no. 4, pp. 577-582, 1995.

[25] K. Shin, D. Chung, and S. Lee, "The effect of consolidation temperature on microstructure and mechanical properties in powder metallurgy-processed 2XXX aluminum alloy composites reinforced with sic particulates," Metallurgical and Materials Transactions A, vol. 28, no. 12, pp. 2625-2636, 1997.

[26] M. Haouaoui, I. Karaman, H. J. Maier, and K. T. Hartwig, "Microstructure evolution and mechanical behavior of bulk copper obtained by consolidation of micro- and nanopowders using equal-channel angular extrusion," Metallurgical and Materials Transactions A, vol. 35, no. 9, pp. 2935-2949, 2004. 

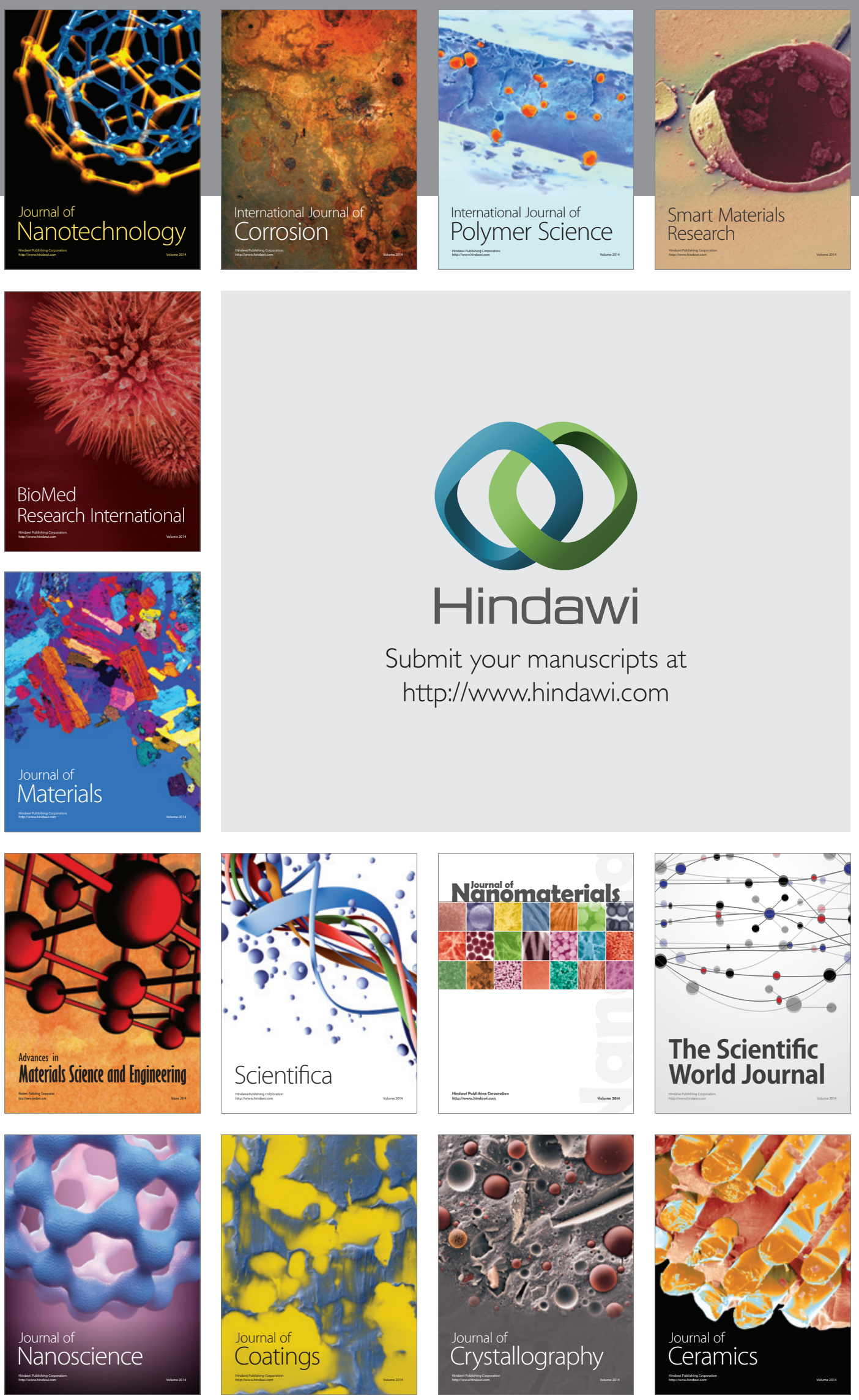

The Scientific World Journal

Submit your manuscripts at

http://www.hindawi.com

\section{World Journal}

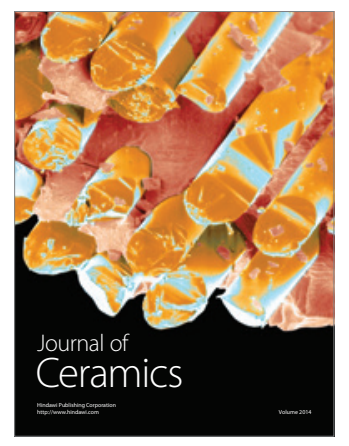

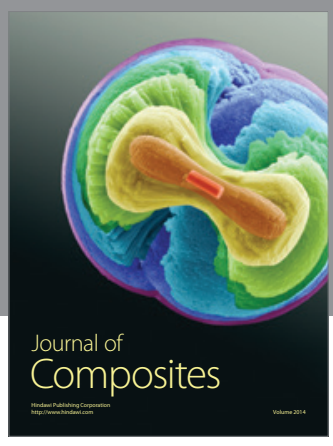
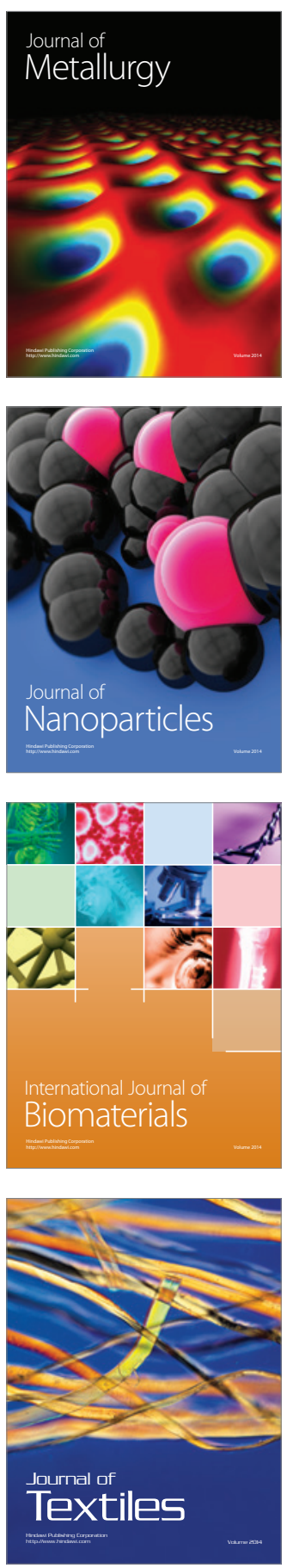